\title{
When and how to use BRS in bifurcations?
}

\author{
Goran Stankovic ${ }^{1 *}, \mathrm{MD}, \mathrm{PhD}$; Jens Flensted Lassen², MD, PhD \\ 1. Department of Cardiology, Clinical Center of Serbia and Faculty of Medicine, University of Belgrade, Belgrade, Serbia; \\ 2. The Heart Centre, Rigshospitalet, University Hospital of Copenhagen, Copenhagen, Denmark
}

The references can be found in the online version of this paper at the following website: http://www.pcronline.com/eurointervention/V_issue/44

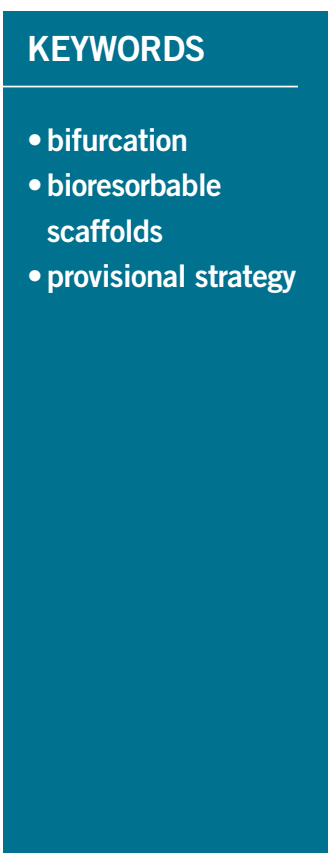

\section{Abstract}

Bioresorbable coronary scaffolds (BRS) may offer potential advantages compared to metallic DES, aiming to restore vessel patency without implanting a permanent prosthesis, which may be especially important for bifurcation treatment. On the other hand, there are some inherent limitations, which may impact on the widespread use of BRS. In the current article we discuss the bench testing data and initial clinical results on BRS use in bifurcation lesions presented during European Bifurcation Club (EBC) meetings and review some of the limited number of published real-world registry results.

*Corresponding author: Department of Cardiology, Clinical Center of Serbia and Faculty of Medicine, University of Belgrade, Visegradska 26, 11000 Belgrade, Serbia.E-mail: gorastan@sbb.rs 


\section{Introduction}

Several bioresorbable coronary scaffold (BRS) designs are currently available, constructed either from polymers or from magnesium alloy ${ }^{1-3}$. BRS may offer potential advantages compared with metallic DES, aiming to restore vessel patency without implanting a permanent prosthesis, which may be especially important for bifurcation treatment. On the other hand, there are some inherent limitations, such as bulky profile and limited expansion capacity, length of time for complete resorption of the Absorb (Abbott Vascular, Santa Clara, CA, USA) BRS (approximately four years), creation of "neointimal bridge" on jailed struts ${ }^{4}$, as well as the signals for increased early scaffold thrombosis demonstrated recently by two large all-comers registries, the GHOST-EU and AMC $\mathrm{A}^{5,6}$, which may impact on the widespread use of BRS. The BRS which has been evaluated most is the bioresorbable everolimus-eluting scaffold Absorb (Abbott Vascular), with the publication of several studies with long follow-up ${ }^{7-9}$. However, the Absorb BRS has been clinically evaluated in simple lesions and the available randomised trials have excluded bifurcations with side branches (SB) exceeding or equal to $2 \mathrm{~mm}$ in diameter. Therefore, bifurcation management with BRS remains challenging. In the current article we discuss bench testing data and initial clinical results on BRS use in bifurcation lesions presented during the $9^{\text {th }}$ and $10^{\text {th }}$ European Bifurcation Club (EBC) meetings, and review some of the limited number of published real-world registry results. The consensus reached represents a revision of the $\mathrm{EBC}$ recommendations for metallic $\mathrm{DES}^{10,11}$

\section{Provisional strategy utilising BRS}

There is general agreement that a provisional strategy should be the default technique when BRS are used for bifurcation treatment ${ }^{11}$.

\section{BRS SELECTION}

Stent selection is still intensely debated: it seems to be a real dilemma as to which strategy should be recommended in different anatomies. The main problem is the restriction of dilatation of the BRS above $0.5 \mathrm{~mm}$ of the reference diameter. One approach is to select the stent according to the distal reference of the main vessel (MV), similar to the recommendation for metallic stents. This strategy, however, may have restrictions when post-dilating the proximal MV due to the mechanical limitations of expanding the stent. In suitable anatomies, another strategy could be to select the stent according to the proximal MV diameter and to deploy at low pressure in order to avoid damaging the distal vessel, followed by adequate post-dilatation of the proximal segment ${ }^{11,12}$. However, the decision on sizing the stent according to the proximal or distal reference diameter depends on the individual coronary anatomy of the patient and is, in the end, the decision of the operator. Importantly, an Absorb BRS should not be used in bifurcations in which the proximal MV diameter is greater than the maximal recommended diameter of the BRS ${ }^{12,13}$.

\section{BRS DEPLOYMENT}

Similar to non-bifurcation lesions, balloon pressure should be increased progressively (2 atm every five seconds) up to nominal pressure: inflation duration of 30 seconds or more is recommended.

\section{OPTIMISATION STRATEGIES}

Based on Murray's law, the proximal optimisation technique (POT) is recommended with BRS but restricted to non-compliant (NC) balloons $0.5 \mathrm{~mm}$ larger than the reference (the maximal recommended diameter for the Absorb BRS because stretching with a larger diameter balloon may cause BRS strut fracture in the proximal vessel $)^{13}$. While single strut fracture may have little clinical impact, multiple scaffold fractures and the protrusion of many struts into the lumen are likely to have adverse consequences ${ }^{14}$. To perform POT, an NC balloon is positioned with the distal balloon marker just proximal to the carina, and then inflated to expand to the diameter of the proximal segment ${ }^{11}$. This inflation decreases the angle of the ostium relative to the proximal MV segment, thus facilitating entry of a guidewire and balloon through the struts into the side branch. Bench testing has demonstrated that POT is safe and a mandatory step in provisional strategy ${ }^{15}$.

The next step is dilatation through the side of the scaffolds, which results in distortion inside the MV but also some protrusion of struts into the $\mathrm{SB}^{12,16}$. To avoid strut fracture, a side branch dilatation with a $3.0 \mathrm{~mm} \mathrm{NC}$ balloon at a maximum of $10 \mathrm{~atm}$ could be used for a $3.0 \mathrm{~mm}$ Absorb BRS ${ }^{12}$. Final POT with an adequately sized NC balloon should be performed in the proximal MV to correct any scaffold malapposition created by side opening (the sequential strategy is "PSP": POT+Side branch opening+final POT) ${ }^{15}$.

Routine final kissing balloon dilatation (FKBD) is not recommended. Recently, FKBD with minimal overlap of two balloons was proposed, positioning the proximal marker of the SB balloon in the MV immediately proximal to the SB ostium ("snuggle balloon dilatation" or "mini-FKBD", depending on the length of SB balloon protrusion) and low-pressure inflation (safe threshold at or below $5 \mathrm{~atm}$ for each NC balloon sized 1:1 to the distal vessel reference) $)^{12,17,18}$. Higher pressures increase the risk of strut fracture $^{12}$. Final POT with an adequately sized NC balloon is recommended (but not essential) to correct any scaffold deformation in the proximal MV (the kissing strategy is "PKP": POT+Snuggle Kissing+final POT $)^{15}$. In bench testing, the PSP and PKP strategies provided similar optical coherence tomography (OCT) and microcomputed tomography (micro-CT) results in the $\mathrm{MV}^{15}$. Intravascular imaging, especially OCT, is also recommended in the clinical setting to guide optimal Abosrb BRS implantation in bifurcation lesions ${ }^{11}$.

\section{Two-stent techniques}

Bench studies and several case reports have demonstrated the feasibility of a number of planned two-stent techniques utilising either two BRS or a combination of BRS and $\mathrm{DES}^{6,19-25}$.

When SB stenting is required as a crossover from provisional, metallic DES or BRS implantation on the SB should be considered utilising for preference the T-stenting technique ${ }^{12,15}$. Preliminary experience with the TAP (T-stenting and small protrusion) technique 
has also demonstrated sufficient SB lumen area without compromising the $M V^{18,24}$. A BRS may be considered for $\mathrm{SB} \geq 2.5 \mathrm{~mm}$ and if the angle with the MV is favourable for the T technique. FKBD should be performed with sequential inflation (SB first followed by MV), and with sequential deflation (MV first followed by SB). FKBD should be performed at a low pressure to avoid scaffold disruption at the orifice of the $\mathrm{SB}$, proximal MV scaffold overdilatation and excessive shift of the scaffold neo-carina and interference with the MV after MV balloon deflation ${ }^{25}$.

According to bench testing data with OCT and micro-CT evaluation, complex techniques like culotte and mini-crush stenting result in MV and SB lumen obstruction, and these techniques should be avoided in order to prevent scaffold strut fractures and excessive overlap related to the thickness of the struts ${ }^{11,12,15}$. Operators need to keep in mind that, in the case of culotte stenting, $300 \mu \mathrm{m}$ of scaffold (Absorb BRS strut thickness $\approx 150 \mu \mathrm{m}$ ) remains in the overlapped region of the proximal MV and, in the case of mini-crush, the triple layer creates approximately $450 \mu \mathrm{m}$ of scaffold on one side, though for a short distance ${ }^{24}$.

When a metallic DES is implanted in the SB as a first step in a planned two-stent strategy, the mini-crush and the sleeve techniques have been reported ${ }^{17,23}$. In conclusion, it is generally agreed that implantation of BRS in bifurcations with SB diameter larger than $2 \mathrm{~mm}$ should be evaluated in randomised trials to facilitate the rapid creation of firm data on efficacy and safety for this promising new technology.

\section{Summary}

Bench testing data and initial clinical results of BRS use in bifurcation lesions seem promising. Simple strategies, with MB stenting followed by POT, and, when needed, SB side opening and final POT or POT with mini-FKBD are recommended. Operators need to understand the difference in the mechanical characteristics of BRS and metallic DES and carefully select device and balloon size and pressures to be utilised. The present recommendations apply to the Absorb BRS and may need to be revised with other stent designs, including the magnesium alloy-based BRS which may have a more predictable behaviour, known from other metallic stents.

\section{Conflict of interest statement}

The authors have no conflicts of interest to declare.

\section{References}

The references can be found in the online version of the paper. 


\section{Online data supplement}

\section{References}

1. Ormiston JA, Webster M, Onuma Y, Serrys PW. Bioresorbable coronary scaffolds, in Coronary Stenting: A companion to Topol's textbook in interventional cardiology. Philadelphia, PA, USA: Elsevier; 2014.

2. Verheye S, Ormiston JA, Stewart J, Webster M, Sanidas E, Costa R, Costa JR Jr, Chamie D, Abizaid AS, Pinto I, Morrison L, Toyloy S, Bhat V, Yan J, Abizaid A. The next-generation bioresorbable coronary scaffold system: from bench to first clinical evaluation. JACC Cardiovasc Interv. 2014;7:89-99.

3. Capranzano P, Gargiulo G, Capodanno D, Longo G, Tamburino C, Ohno Y, Attizzani GF, La Manna A, Di Salvo M, Francaviglia B, Grasso C, Sgroi C, Tamburino C. Treatment of coronary bifurcation lesions with bioresorbable vascular scaffolds. Minerva Cardioangiol. 2014;62:229-34.

4. Okamura T, Onuma Y, Garcia-Garcia HM, Regar E, Wykrzykowska JJ, Koolen J, Thuesen L, Windecker S, Whitbourn R, McClean DR, Ormiston JA, Serruys PW; ABSORB Cohort B Investigators. 3-Dimensional optical coherence tomography assessment of jailed side branches by bioresorbable vascular scaffolds: a proposal for classification. JACC Cardiovasc Interv. 2010;3: 836-44.

5. Kraak RP, Hassell ME, Grundeken MJ, Koch KT, Henriques JP, Piek JJ, Baan J Jr, Vis MM, Arkenbout EK, Tijssen JG, de Winter RJ, Wykrzykowska JJ. Initial experience and clinical evaluation of the Absorb bioresorbable vascular scaffold (BVS) in real-world practice: the AMC Single Centre Real World PCI Registry. EuroIntervention. 2015;10:1160-8.

6. Capodanno D, Gori T, Nef H, Latib A, Mehilli J, Lesiak M, Caramanno G, Naber C, Di Mario C, Colombo A, Capranzano P, Wiebe J, Araszkiewicz A, Geraci S, Pyxaras S, Mattesini A, Naganuma T, Munzel T, Tamburino C. Percutaneous coronary intervention with everolimus-eluting bioresorbable vascular scaffolds in routine clinical practice: early and midterm outcomes from the European multicentre GHOST-EU registry. EuroIntervention. 2015;10:1144-53.

7. Garcia-Garcia HM, Schultz C, Duckers E, Regar E, Ligthart J, Serruys PW, van Geuns RJ. Five-year follow-up of the ABSORB bioresorbable everolimus-eluting vascular scaffold system: multimodality imaging assessment. EuroIntervention. 2013;8:1126-7.

8. Karanasos A, Simsek C, Gnanadesigan M, van Ditzuhuijzen NS, Freire R, Kijkstra J, Tu S, van Mieghem N, van Soest G, de Jaegere P, Serruys PW, Zijlstra F, van Geuns RJ, Regar E. OCT assessment of the long-term vascular healing response 5 years after everolimus-eluting bioresorbable vascular scaffold. J Am Coll Cardiol. 2014;64:2343-56.

9. Onuma Y, Dudek D, Thuesen L, Webster M, Nieman K, Garcia-Garcia HM, Ormiston JA, Serruys PW. Five-year clinical and functional multislice computed tomography angiographic results after coronary implantation of the fully resorbable polymeric everolimus-eluting scaffold in patients with de novo coronary artery disease: the ABSORB cohort A trial. JACC Cardiovasc Interv. 2013;6:999-1009.

10. Stankovic G, Lefevre T, Chieffo A, Hildick-Smith D, Lassen JF, Pan M, Darremont O, Albiero R, Ferenc M, Finet G, Adriaenssens T, Koo BK, Burzotta F, Louvard Y; European Bifurcation Club. Consensus from the 7 th European Bifurcation Club meeting. EuroIntervention. 2013;9:36-45.

11. Lassen JF, Holm NR, Stankovic G, Lefevre T, Chieffo A, Hildick-Smith D, Pan M, Darremont O, Albiero R, Ferenc M, Louvard Y. Percutaneous coronary intervention for coronary bifurcation disease: consensus from the first 10 years of the European Bifurcation Club meetings. EuroIntervention. 2014;10:545-60.

12. Ormiston JA, Webber B, Ubod B, Webster MW, White J. Absorb everolimus-eluting bioresorbable scaffolds in coronary bifurcations: a bench study of deployment, side-branch dilatation and post-dilatation strategies. EuroIntervention. 2015;10:1169-77.

13. McGeoch RJ, Tanaka K, Overgaard CB, Bezerra HG, Dzavik V. Proximal optimization technique and kissing balloon inflations with the bioresorbable vascular scaffold for coronary bifurcation percutaneous coronary intervention. Can J Cardiol. 2014;30:1461.e5-7.

14. Ormiston J, De Vroey F, Serruys PW, Webster M. Bioresorbable polymeric vascular scaffolds: a cautionary tale. Circ Cardiovasc Interv. 2011;4:535-8.

15. MotreffP, Darremont O, Leymarie JL, Lefevre T, Souteyrand G, Combaret N, Lamer M, Pilet P, Guerin P. BVS Bench Testing. 10th European Bifurcation Club Meeting, Bordeaux, October 17-18, 2014. http://www.bifurc.net/files/medtool/webmedtool/icpstool01/ stud0638/pdf00001.pdf accessed on January 10, 2015.

16. Ormiston JA, Webster MW, Ruygrok PN, Stewart JT, White HD, Scott DS. Stent deformation following simulated sidebranch dilatation: a comparison of five stent designs. Catheter Cardiovasc Interv. 1999;47:258-64.

17. Dzavik V, Colombo A. The absorb bioresorbable vascular scaffold in coronary bifurcations: insights from bench testing. JACC Cardiovasc Interv. 2014;7:81-8.

18. Seth A, Sengottuvelu G, Ravisekar V. Salvage of side branch by provisional "TAP technique" using Absorb bioresorbable vascular scaffolds for bifurcation lesions: first case reports with technical considerations. Catheter Cardiovasc Interv. 2014;84:55-61.

19. Attizzani GF, Ohno Y, Capranzano P, La Manna A, Francaviglia B, Grasso C, Sgroi C, Tamburino C, Longo G, Fujino Y, Capodanno D, Tamburino C. Initial experience of percutaneous coronary intervention in bifurcations with bioresorbable vascular scaffolds using different techniques--insights from optical coherence tomography. Int J Cardiol. 2013;170:e33-5.

20. Grundeken MJ, Hassell ME, Kraak RP, de Bruin DM, Koch KT, Henriques JP, van Leeuwen TG, Tijssen JG, Piek JJ, 
de Winter RJ, Wykrzykowska JJ. Treatment of coronary bifurcation lesions with the Absorb bioresorbable vascular scaffold in combination with the Tryton dedicated coronary bifurcation stent: evaluation using two- and three-dimensional optical coherence tomography. EuroIntervention. $2014 \mathrm{Aug}$ 30. [Epub ahead of print].

21. Fernandez D, Brugaletta S, Martin-Yuste V, Regueiro A, de Mingo A, Santos A, Masotti M, Sabaté M. First experience of a bioresorbable vascular scaffold implantation in left main stenosis. Int J Cardiol. 2013;168:1566-8.

22. Dzavik V, Muramatsu T, Crooks N, Nakatani S, Onuma Y. Complex bifurcation percutaneous coronary intervention with the Absorb bioresorbable vascular scaffold. EuroIntervention. 2013;9:888.
23. Jim MH. No-kiss sleeve: a technical modification of the sleeve technique to treat true bifurcation lesions in the bioresorbable vascular scaffold era. Int J Cardiol. 2014;176:532-4.

24. Miyazaki T, Costopoulos C, Sato K, Naganuma T, Panoulas VF, Figini F, Latib A, Colombo A. Strategy for optimal side-branch positioning of bioresorbable vascular scaffolds in dedicated 2-stent techniques: insights from optical coherence tomography. Cardiovasc Revasc Med. 2014;15:298-300.

25. Miyazaki T, Latib A, Colombo A. Provisional hybrid 2-stent strategy utilizing bioresorbable vascular scaffold and drug-eluting metal stent; 'T-stenting and small protrusion' technique. Catheter Cardiovasc Interv. 2014 Dec 15. [Epub ahead of print]. 